\title{
Progressing a Sustainable-world: A Socio-ecological Resilience Perspective
}

\author{
Don Clifton \\ University of South Australia \\ City West Campus, North Terrace, Adelaide, South Australia \\ Tel: 61-8-8463-0850Ｅ-mail: doncmail@bigpond.net.au
}

\begin{abstract}
This paper identifies two approaches to how humanity might go about living sustainably, that is, for there to be a sustainable-world, namely; (a) the Reformist-approach, which is the current dominant sustainable-world approach consistent with mainstream sustainable-development, and (b) the Transformational-approach. The concept of socio-ecological-resilience is used to critique these two approaches to consider which is more likely to see the primary sustainable-world goal - the flourishing of life, incorporating human and ecological wellbeing, maintained over an indefinite time frame - achieved. The critique suggests that Reformism is challenging to believe as a credible pathway for humanity. Instead, Reformism is shown, in a number of important respects, to undermine the resilience of the socio-ecological-systems on which human and ecological wellbeing depends. A more determined effort to fully implement the Reformist-approach will not solve these problems - the approach is, in a number of key respects, inherently resilience eroding and self-defeating. The Transformational-approach is instead shown to be more consistent with socio-ecological-resilience principles and is, in this respect, a
\end{abstract} preferred sustainable-world approach for humanity to pursue.

Keywords: Sustainable-world, Reformist-approach, Transformational-approach, Resilience, Socio-ecological-resilience

\section{Introduction}

The need for humanity to live sustainably, that is, for there to be a 'sustainable-world', has roots dating back thousands of years in concerns expressed at the environmental damage humans cause (Hughes, 2001). Following the 1987 release of the World Commission on Environment and Development's report "Our Common Future" (WCED, 1987), and a series of follow-up United Nations sponsored international events (Blewitt, 2008; Speth \& Haas, 2006), the sustainable-world concept, often expressed as sustainable-development, has become embedded in national and international political circles, in the business sector, in the agendas of a broad range of NGOs, social groups, and research organisations, and in many academic and professional disciplines (Clifton \& Amran, 2010).

Despite this, humanity is not living sustainably. Absolute poverty continues to affect hundreds of millions of people (Bell, 2009; Rees, 2008), the resource-use gap between the rich and the poor is increasing (Bell, 2009; Rees \& Westra, 2003), the Earth's ecosystems continue to deteriorate (Brown, 2008; UNEP, 2007), atmospheric green-house-gas loads continue to rise driving global warming and ocean acidification (IPCC, 2010; UNEP, 2009), and humanity's use of the Earth's renewable resource base continues to exceed its rate of regeneration, with this unsustainable rate of use accelerating (Footprint Network, 2010; Rockström et al., 2009).

Why, however, after all of the attention the need for humans to live sustainably has attracted, do these problems persist? This paper reports on a component of a current research project (the 'Project') that considers this question. (For an overview of the entire Project, see Clifton (2010b)). Specifically, this paper applies the concept of socio-ecological-resilience to critique the current dominant sustainable-world approach, to consider if this approach is part of the problem. That is, the paper questions whether the current dominant sustainable-world approach it is able to deliver its promised outcomes, regardless of how aggressively it is pursued.

In conducting this critique, the paper proceeds as follows. Section 2 provides an overview of what it means for there to be a sustainable-world. Section 3 presents an overview of the socio-ecological-resilience concept as evident in the literature, with section 4 discussing the linkages between resilience and a sustainable-world. Section 5 gives a brief overview of the process that was followed in conducting the critique of the different sustainable-world approaches (as per section 2) in resilience terms (as per section 3). A summary of the findings of this critique is included in Appendix 2, and it is this application of the socio-ecological-resilience concept to the broad range of dimensions that constitute what it means for there to be a sustainable-world that is the main contribution to the literature that this paper makes.

Section 6 discusses some of the key themes that arose from the critique. Section 7 concludes with some summary observations and brief comments on the contribution to knowledge, limitations, and areas for future research that arose from the critique.

\section{A sustainable-world}

\subsection{A pluralistic and contested concept}

A sustainable-world is a vague and pluralistic concept, grounded in differing value systems, perceptions of reality, and cultural contexts (Gibbs \& Krueger, 2005; Osorio, Lobato, \& Castillo, 2005), making it ill suited to 
expression of its meaning by way of a single and concise definition (Dobson, 1996). As part of the Project on which this paper is based, a review of the literature was conducted to consider the meaning of a sustainable-world within this pluralistic and contested space. From this review, a sustainable-world typology ('SWT') was developed, an abridged version of which is incorporated in Appendix 2. (Reference in this paper to items in the SWT are shown as 'SWT item xx'; for a full version of the SWT, including the process by which it was developed, see Clifton (2010a)). The SWT shows two main sustainable-world approaches evident in the literature, namely the Reformist-approach and the Transformational-approach.

\subsection{Reformist-approach}

The Reformist-approach sees the achievement of a sustainable-world in terms of reforming the current dominant socio-economic system through changes at the margin to make this system more environmentally responsible and socially just ('green-and-just'). Key characteristics of this approach include: (a) an anthropocentric bias, in the form of weak-anthropocentrism, (b) human needs met through a focus on the consumption of goods and services produced and consumed in green-and-just ways, (c) human population policies focused on stabilising population numbers, (d) human development, including poverty elimination, progressed by continued economic growth and technology advance, but done in green-and-just ways, (e) continuation of the current globalisation and free-trade agenda to underpin these economic and social goals, and (f) technological advance to drive growth, improve human wellbeing, and address any consequential negative ecological impacts that are harmful to human wellbeing.

\subsection{Transformational-approach}

The Transformational-approach is quite different. It sees the achievement of a sustainable-world as requiring fundamental and transformational socio-economic system change. Key features include: (a) an ecocentric ethic, (b) human needs met through consumptive sufficiency and a focus on non-material satisfiers, (c) the need for a long-term reduction in human population numbers and an increase in the populations of most non-human species, (d) poverty as best resolved through resource reallocation, not more global resource-through-put growth, with a key role for the politically and economically powerful, especially the industrialised North, to cease the exploitation of resources from the politically and economically weak, and (e) constraints placed on the use of the Earth's natural resources such that it remains well within ecosystem limits.

\subsection{Primary sustainable-world goal}

Despite these differences, both approaches share a common primary sustainable-world goal, namely 'the flourishing of life, incorporating human and ecological wellbeing, maintained over an indefinite time frame, with this wellbeing grounded in principles of intra-generational and inter-generational justice'.

\subsection{Dominant sustainable-world approach}

Reformism is the current dominant sustainable-world approach (Gould \& Lewis, 2009; Handmer \& Dovers, 1996), and is consistent with mainstream sustainable-development narratives at national and international political levels, and within business circles (Castro, 2004; J. Robinson, 2004). In this respect, Reformism's dominance lies in it being the approach espoused by the key power centres of society. (Note: although the sustainable-development term is not used exclusively in the Reformist context, it has strong historical links to Reformism (Escobar, 1995; Orton, 1990). As such, the more neutral sustainable-world term is used in this paper as a general label for humanity living sustainably).

\section{Resilience}

\subsection{Background}

Current day use of the resilience concept within the sustainable-world context is generally dated from the early 1970's and the ecological systems research of Holling (Schoon, 2005; Walker et al., 2006). From this, two main forms of resilience are now evident in the literature as relevant to sustainable-world issues, namely: (a) engineering-resilience, and (b) ecological or, alternately, socio-ecological, resilience.

\subsection{Engineering resilience}

Engineering-resilience is concerned with the ability of a system to resist disturbance, but if disturbance does cause system disruption, it is concerned with speed of recovery (i.e., bounce-back) to the pre-disturbance state. It incorporates concepts of efficiency, predictability, and constancy, and sees systems as having an optimal state where resilience is based on the maintaining of efficiency of function at this optimal state (Folke et al., 2010; Holling, 1996). This form of resilience is seen as the current dominant social approach to resilience (Handmer \& Dovers, 1996), the way in which people mostly talk of resilience in day-to-day life (Walker \& Salt, 2006), and as the historically dominant approach of mainstream natural resource management, based around attempts to control natural resource flows in an optimising manner (Folke, 2006).

Three main criticisms are raised against pursuing engineering-resilience as a primary sustainable-world resilience strategy. First is that applying engineering-resilience to social and ecological systems is fundamentally flawed - it applies a mechanistic-systems view to a complex-adaptive-systems setting to which it is not suited (Holling, 1996; Princen, 2005). Next, by focusing on resistance and speed of return to the prior equilibrium state, engineering-resilience fails to recognise the idea of thresholds, and fails to address situations where systems can 
be subject to disturbance such that they are unable to bounce-back at all (Peterson, Allen, \& Holling, 1998; Walker \& Salt, 2006). Finally, although engineering-resilience may, by its focus on systems efficiency, improve social and/or ecological system productivity and stability in the short term, its optimisation approach progressively eliminates system spare capacity and redundancy, which reduces the range and magnitude of disturbance which a system can withstand and still continue to function - the greater the focus on engineering-resilience, the less ecologically-resilient a system becomes (Walker \& Salt, 2006).

These concerns do not mean that engineering-resilience is irrelevant in the sustainable-world context. It has an important role and should form part of an overall resilience approach (Gunderson, Allen, \& Holliday, 2010a; Handmer \& Dovers, 1996) - for example, a community building its infrastructure to resist damage from a storm or fire and, after such an event, quickly bouncing-back to normal functioning. Problems arise when the engineering-resilience approach dominates such that it undermines the ability of social and ecological systems to adapt and change within the dynamic space in which they function.

3.3 Socio-ecological resilience

An alternate conceptualisation of resilience has its groundings in ecology as ecological-resilience, where resilience refers to the magnitude of disturbance a system can absorb yet still maintain its core functions, structure, identity, and behaviours (Gunderson et al., 2010a; Holling, 1996). This view of resilience has since been applied: (a) in the broader socio-ecological-systems context, where socio-ecological-systems are conceived as the collective of social and ecological systems, including their interactions, but viewed in an holistic way whereby any distinction between the social and ecological is seen as arbitrary (Adger, 2006; Walker \& Salt, 2006), and (b) more generally, within the context of complex-adaptive-systems (e.g., see Folke et al. (2002; 2010)).

This evolution of the way ecological-resilience is conceived and applied has given rise to a broader description of resilience in the socio-ecological and complex-adaptive systems contexts, namely:

(1) the amount of disturbance a system can absorb and still remain within the same state or domain of attraction.

(2) the degree to which the system is capable of self-organization (versus lack of organization, or organization forced by external factors), and

(3) the degree to which the system can build and increase the capacity for learning and adaptation" (Folke, 2006, pp. 259-260).

The resilience terminology used in this broader context varies in the literature, with a tendency towards socio-ecological or social-ecological resilience. In this paper, the term 'socio-ecological-resilience' is used to signify its application to socio-ecological-systems within the sustainable-world context. Unless otherwise specified, in the remainder of this paper, use of the term 'resilience' will refer to this socio-ecological form of resilience.

In contrast to engineering-resilience, socio-ecological-resilience is concerned with maintenance of system function, self-organisation, learning, and adaptation. It sees socio-ecological-systems as having many possible functional states, and subject to natural variability, change, and unpredictability (Holling, 1996). For socio-ecological-resilience thresholds are paramount and, rather than being focused only on bounce-back, is concerned with increasing the likelihood that a socio-ecological-system does not breach thresholds that move it into an undesirable regime, especially one from which it may not be able to recover (Walker \& Salt, 2006).

\section{Resilience and a sustainable-world}

A number of authors (e.g., Handmer \& Dovers (1996), Holling (1996), and Walker \& Salt (2006)) have made the point that resilience is fundamental to there being a sustainable-world. The key point to be noted from this linkage is that in the sustainable-world context, a system "remain[ing] within the same state or domain of attraction" (see section 3.3 (above)) is concerned with the ability of socio-ecological-systems to continue to meet the primary sustainable-world goal - the flourishing of life, incorporating human and ecological wellbeing, maintained over an indefinite time frame - and to do so regardless of what changes might occur to these systems over time. In this respect, the resilience and sustainable-world concepts are inseparable. This inseparable link sees resilience as a useful tool to consider which of the sustainable-world approaches, Reformist or Transformational, is preferable in the sense of it being more likely to result in the primary sustainable-world goal being achieved.

The remainder of this paper reports on the findings of a resilience critique of the full sustainable-world typology (SWT) content, that was conducted as part of the Project on which this paper is based, to consider this 'which-is-preferable?' question.

Before proceeding, one point of clarification is necessary. In one respect, the Transformational-approach identifies itself as having a resilience focus as per SWT item 5.4, which shows the Transformational approach to risk and precaution in terms of "Resilience living ....socio-ecological-resilience living pursued instead of human activity strategies oriented to maximisation and optimization". As such, it may be claimed as self-evident that the Transformational-approach is, in resilience terms, the preferred sustainable-world approach. This 'resilience 
living' claim of the Transformational-approach is, however, merely a claim about one of the many dimensions set out in the SWT. It does not show if the Transformational-approach is preferable to Reformism when all of the SWT dimensions are considered, and even if it is preferred, it does not show in a meaningful way why this is the case. The critique, as reported in this paper, addresses these broader issues.

\section{Process}

In conducting the resilience critique of the Reformist and Transformational approaches, the following process was followed.

First, a literature review was undertaken: (a) to identify key characteristics incorporated in the socio-ecological-resilience concept, and for each of these characteristics, (b) to identify the way in which they contribute to, or detract from, this form of resilience. The characteristics identified were Adaptability/adaptive-capacity, Diversity, Exposure, Integrity, Modularity, Rate of change, Redundancy, Sensitivity, Spare capacity, Thresholds, and Vulnerability. A table summarising the key features of these characteristics is shown as Appendix 1.

Next, the Reformist and Transformational approaches, as set out in the SWT, were critiqued in terms of: (a) each of the Appendix 1 characteristics, and (b) the content of the broader resilience literature that has a focus on issues relevant to the sustainable-world concept. This critique identified, for each of the SWT dimensions, which sustainable-world approach is preferable in resilience terms and why this is the case. It is this critique that is the key contribution to the literature this paper presents. A brief summary of some of the key points arising from this critique is incorporated in Appendix 2. (Note: detailed analysis documents for both the Appendix 1 and Appendix 2 content are available from this paper's author).

From there, the overall findings were reviewed to consider, across all of the SWT dimensions, which sustainable-world approach is, in resilience terms, more likely to see the primary sustainable-world goal achieved.

\section{Findings and discussion}

The findings show that, from a resilience perspective, Reformism is troublesome, with the Transformational-approach more likely to see the primary sustainable-world goal achieved. This preference for the Transformational-approach extends over all of the dimensions shown in the SWT.

Rather than elaborating on these finding by a line-by-line review of the Appendix 2 content, the remainder of this section considers three of the main themes that emerged from the critique, which will hopefully serve as a useful guide to a reading of Appendix 2.

\subsection{Anthropocentrism - ecocentrism}

\subsubsection{Overview}

The first major theme relates to the implications that flow from the anthropocentric vs. ecocentric paradigms on which the Reformist (anthropocentric) and Transformational (ecocentric) approaches are based. This aspect of alternate views of how a sustainable-world is conceived is well rehearsed in the literature, although the resilience implications have received little direct attention.

For Reformism, its anthropocentric orientation is framed within a weak-anthropocentric view, that is, one where (a) humanity is seen as separate from Nature (i.e., it supports a human-Nature dualism view), (b) human interest satisfaction, for the most part, takes precedence over non-human life, and (c) non-human life is mostly considered in terms of its instrumental value to humans in satisfying 'considered human preferences' (Norton, 2003; Palmer, 2003; Taylor, 2003) ('SWT item 1.2'). Considered human preferences are "any desire or need that a human individual would express after careful deliberation, including a judgment that the desire or need is consistent with a rationally adopted world view" (Norton, 2003, p. 164) which, in this current setting, is a rationally adopted view of a sustainable-world.

A requirement for human acts towards Nature to be based on considered preferences permeates throughout the sustainable-world literature. These considered preferences include a concern for: (a) the interests of future generations, (b) the wellbeing of all members of the current generation, and (c) the cultural, spiritual, and amenity values of Nature as opposed to its mere economic value (Hargrove, 2003; Light \& Rolston, 2003; Palmer, 2003). In this respect, the critique shows that weak-anthropocentrism presents a much broader set of decision making criteria to protect Nature in order to progress human wellbeing than does the traditional 'strong-anthropocentric' approach evident within the neo-classical economic paradigm. This strong-anthropocentric approach sees meeting human needs and wants in relatively narrow self-interest terms based on the satisfaction of 'felt human preferences', that is, "any desire or need of a human individual that can at least temporarily be sated by some specifiable experience of that individual" (Norton, 2003, p. 164). Despite this advance over strong-anthropocentrism, weak-anthropocentrism still places human decisions and acts towards Nature, that are intended to progress the achievement of the primary sustainable-world goal, within the realm of identifiable human interests and within the cultural context in which those interests are determined (Light \& Rolston, 2003). 
Human knowledge of how ecological systems function, and what the impacts of human interventions might be is, however, incomplete and subject to: (a) risks (i.e., statistical probabilities of an event occurring, and the seriousness of the consequences should it occur, are known, but what may happen in any specific instance is not known), (b) uncertainty (i.e. when the direction of change and possible nature of outcomes are believed known but cannot be accurately quantified), and (c) ignorance (i.e. when the direction of change or broad nature of outcomes is unclear, and where threshold effects, surprise, and chaotic processes may operate) (H. Daly \& Farley, 2004; Diesendorf, 1997). Further, uncertainty and ignorance are not necessarily the result of a lack of knowledge, but can instead be the outcome of the fundamental properties of natural systems (as complex-adaptive-systems) that cannot be resolved through further knowledge gain (H. Daly \& Farley, 2004; Handmer \& Dovers, 1996).

The Appendix 2 findings show that, from a resilience perspective, human acts towards Nature that are based on weak-anthropocentric principles, but where this decision making is itself subject to limitations of knowledge and cultural-myopia, risks imposing changes onto Nature that are resilience eroding in material and problematic ways. This erosion can come in a number of forms including: (a) inadvertently reducing biodiversity and ecosystem redundancy in ways detrimental to long-term ecological and human wellbeing, (b) increasing the exposure of ecosystems to harm buy say, imposing change of greater magnitude than might otherwise be the case had knowledge of the implications of actions been more complete, and (c) imposing too fast a rate of change on ecosystems such that the implications of change are not evident until well after the change event has occurred. The human-nature dualism view of weak-anthropocentrism can also aggravate these risks as it sees humans experience themselves as separate from Nature, reducing identification with ecological damage, leading to greater ecological harm and less motivation to resolve ecological problems (Conn, 1995).

On the other hand, the ecocentric approach provides a basis for protecting Nature where no human interest is apparent. Nature is seen as having value for its own sake, where protecting Nature is not conditional on it satisfying an instrumental-use-to-humans condition (CODP, 2003; Light \& Rolston, 2003). In addition, ecocentrism rejects weak-anthropocentrism's human-Nature dualism and, as such, is not as exposed to the separation-risks this dualism view presents. In these respects, the Appendix 2 findings show that ecocentrism increases the functional diversity and response diversity in human decision making and action towards Nature beyond that evident in weak-anthropocentrism - it presents additional decision making criteria for protecting Nature, and response options in the event of harm to Nature. This greater functional and response diversity can help reduce the risks of human decision-making errors that result in a degrading of ecological integrity, from which flow-through erosion of human wellbeing may occur.

In these respects, the Transformational-approach is a preferred sustainable-world approach in resilience terms. Reformist weak-anthropocentrism, although offering a substantial advance on the strong-anthropocentrism narrative, still leaves human decision making towards Nature open to greater risks of error, and consequential hampering of achievement of the primary sustainable-world goal, than does the Transformational ecocentric approach.

\subsubsection{Counter claims}

There are, however, a number of counter-claims against this preference for Transformational ecocentrism over Reformist weak-anthropocentrism, some of the more prominent being as follows.

Firstly, some argue that ecocentrism "open[s].. the doors to an anti-humanist morality that risks sacrificing human well-being for the sake of an ill-defined 'greater good" (CODP, 2003) and that, by being opposed to human centeredness, it is opposed to humans and is misanthropic (Fox, 1995). In this view: (a) ecocentrism, rather than contributing to human and ecological wellbeing, might benefit the ecological but, in doing so, harms the human, (b) this undermines the achievement of the primary sustainable-world goal from a human wellbeing perspective and, in this respect, (c) the Transformational-ecocentric approach is not consistent with resilience objectives when applied to the achievement of the primary sustainable-world goal.

This misanthropic claim is, however, misguided. It commits the "fallacy of misanthropy" (Fox, 1995, p. 19) as the claim does not follow from an ecocentric view. Instead, ecocentrism is a concern for all life, not one form to the exclusion of another (Fox, 1995; Rodman, 1995; Taylor, 1989). The Transformational-approach does not reject, as a valid and important basis for human decision making, the weak-anthropocentric notion of Nature being of instrumental value for the meeting of considered human preferences. It does, however, reject the weak-anthropocentric claim that the non-human world is of only (or mostly) instrumental value to humans and holds that, in addition, Nature also has value for its own sake. There is nothing untoward about this position. The idea of something possessing both instrumental value and value for its own sake is well recognized in the literature (Light \& Rolston, 2003; O'Neill, Holland, \& Light, 2008; UHK, 2010) and something we see in everyday life - say, a parent who values a child for its own sake but nonetheless receives instrumental benefits from the child (love, affection, pleasure, and so on).

The anti-humanist claim against ecocentrism also seems to assume that ecocentric decision making, being based on principles that include the non-human world as having value for its own sake, is necessarily human wellbeing eroding. There is, however, no reason to presume that this claimed human wellbeing erosion needs to occur. 
Human wellbeing can be achieved in many and varied ways and, for its advocates, the ecocentric approach is seen to offer greater ecological security for humans (Wackernagel \& Rees, 1997) and, more broadly, increased human wellbeing through a stronger and deeper connection with Nature (Brown, 1995; Cato, 2009; Naess, 1989), than can be found within the weak-anthropocentric paradigm.

In summary, any claims that ecocentrism is anti-humanist, in that it risks sacrificing human wellbeing for the sake of the non-human, are ill-founded and are based on a misreading of the ecocentric view. Further, any flow-on claims that the Transformational-ecocentric approach may undermine human wellbeing and hence be inconsistent with resilience principles within the sustainable-world context are equally ill-founded.

Next is a view that, in practice, weak-anthropocentrism will produce very similar outcomes to ecocentrism when it comes to the protection of Nature (for a detailed review of this claim, see Minteer (2009)). In this respect, weak-anthropocentrism is presented as a preferred approach as it is claimed to be: (a) one to which humans can better identify than ecocentrism, where ecocentrism is seen as more 'metaphysical', and (b) one more likely to succeed in the public policy and business arenas where action to protect Nature is more likely to be taken if clear links to human wellbeing can be identified (Hanna, 1995; Hargrove, 2003; Holdren, Daily, \& Ehrlich, 1995). In this view, ecocentrism can be seen as resilience eroding as, when it comes to gaining support for actions to protect Nature, government, business, and the community generally will be less motivated to act if arguments are presented in ecocentric terms as compared to weak-anthropocentric terms. Further, as a weak-anthropocentric approach is seen to be able to effectively deliver the same protection of Nature as would an ecocentric approach, nothing is lost in taking this weak-anthropocentric position.

There are two main problems with this argument. The first is that the claim falls foul of the same misrepresentation of the ecocentric approach as for the misanthropy claim (as discussed above). The ecocentric approach has no objection to arguing a case for the protection of Nature based on weak-anthropocentric principles - the objection is to making decisions based only on weak-anthropocentric principles and ignoring the broader ecocentric value set. The second problem is that, despite some claims that weak-anthropocentrism and ecocentrism will produce similar outcomes to the protection of Nature, this is not how these two approaches play out in the Reformist-Transformational space. The Reformist position portrays the meeting of non-human interests, and the way in which humanity interacts with Nature, in ways that are fundamentally different to the Transformational view.

The final counter claim that will be considered here proposes that there is no reason why allowance cannot be made within the Reformist-approach for the knowledge and cultural-myopia constraints within which human decision making is made. In fact, not only can Reformism allow for this, it does so, as evident in SWT item 5.4, through recognition of ignorance and uncertainty, and application of the precautionary-principle ('PP') to address these human decision-making constraints. As such, the claimed increased risk exposure in following the Reformist-approach, as compared to the Transformational-approach, may simply not exist in any material way.

This argument also presents two main problems. The first is that for Reformism, application of the PP is based on weaker versions of this principle than applies for the Transformational-approach. It is beyond the scope of this paper to explore in detail the implications of applying weak vs. strong versions of the PP (for a discussion on this issue, see Cranor (2004), Dorman (2005), and Beder (2006)). The key point however is that weaker versions of the PP, along the lines of those found in various United Nations documents such as the Rio Declaration (UN, 1992a) and the Framework Convention on Climate Change (UN, 1992b), provide a number of 'escape provisions' for social actors (government, business, etc) when considering action to protect the environment, which are not as evident in stronger PP formulations. The second problem is that Reformism, in a number of important ways, frames a sustainable-world within the context of the maximization (the most of) and optimisation (the most out of) of human activity and resource productivity. In this context, the role of the PP is constrained to addressing uncertainty and ignorance in human knowledge as it relates to the processes by which this maximisation and optimisation strategy is pursued, as opposed to questioning whether this strategy should be pursued at all. This leads to the second major theme evident in the findings summarised in Appendix 2, that being the scale of human activity.

6.2 Scale of human activity

\subsubsection{Overview}

Both the Reformist and Transformational approaches are concerned with flourishing lives, although they differ substantially in how this is to be achieved. For Reformism, efforts to achieve flourishing lives within the human domain are incorporated within strategies directed at maximising human activity, evident in its focus on: (a) continuous strong global economic growth (SWT item 5.5), (b) the related consumption of goods and services to meet human needs and wants that flow from, and drive, this growth (SWT item 3.2.1.), and (c) an orientation to maximising the human population that can be sustained within the broader Reformist sustainable-world criteria (SWT item 3.3.1.). This approach, however, presents a number of challenges when viewed from a resilience perspective.

First, maximising human activity comes at a cost to the non-human world. For Reformism, much of the narrative towards protecting Nature is not in terms of ensuring its abundance, but ensuring that its transformation by 
humans does not continue beyond a point that breaches critical levels. In particular, the focus is on maintaining critical levels of biodiversity (SWT item 3.3.2) and, more broadly, critical levels of natural capital ('K $\mathrm{K}_{\mathrm{N}}$ ) (SWT item 5.3) (with $\mathrm{K}_{\mathrm{N}}$ referring to aspects of Nature that provide a flow of goods and services that are useful to humans (H. E. Daly, 1996; Porritt, 2005)). What is critical in this context refers to what is critical for satisfying human considered preferences within a weak-anthropocentric paradigm (SWT item 1.2).

Within the Reformist weak-sustainability approach to resource management (SWT item 5.3), this focus on critical $\mathrm{K}_{\mathrm{N}}$ levels effectively sanctions the erosion of $\mathrm{K}_{\mathrm{N}}$ where there is an apparent economic advantage in doing so (Holland, 1997). The Appendix 2 findings show that this $\mathrm{K}_{\mathrm{N}}$ erosion carries with it a corresponding reduction in ecosystem spare capacity, pushing these systems closer to thresholds, and increasing their vulnerability to harm. Further, and as discussed in section 6.1 , what critical $\mathrm{K}_{\mathrm{N}}$ levels are may simply be unknown or unknowable - incomplete knowledge and cultural-myopia in human decision making may see these levels inadvertently breached, from which recovery may simply not be possible within any meaningful human time scale (Dietz \& Neumayer, 2007; Pearce \& Atkinson, 1998; Turner, 1992). These ecosystem resilience problems also spill over to the social systems setting, by increasing the exposure of social systems to the consequences of more frequent and substantial ecosystems shocks - say, storm damage, and crop failure from drought, as a result of atmospheric green-house-gas thresholds being pressed. Alternately, the Transformational approach, with its focus on abundance within the Natural world (SWT items 3.3.2, 5.3, and 5.6.1) presents an approach more consistent with resilience principles.

Next, to support this maximisation of human activity strategy, Reformism seeks to optimise renewable natural resource (' $\mathrm{K}_{\mathrm{NR}}$ ') productivity (SWT item 3.2.2) to provide the resource flows necessary to meet human needs and wants (SWT item 3.1). However, as discussed in section 3.2, this focus on $\mathrm{K}_{\mathrm{NR}}$ optimisation is fundamentally at odds with socio-ecological-resilience principles. Optimisation, through the elimination of unused (spare) capacity and redundancy (as functional and response diversity) - examples include the reduction in crop and livestock diversity that has paralleled the spread of modern industrial agricultural methods (Shiva, 2000; UNEP, 2007) - may increase output in the short-term but in the longer-term, undermines ecosystem resilience and increases vulnerability to disturbance (Walker \& Salt, 2006). In effect, the long-term sustainability of resource flows from the $\mathrm{K}_{\mathrm{NR}}$ base is being sacrificed for short-term productivity optimisation.

Thirdly, Reformism's focus on the maximisation of human activity drives a rate of change within socio-ecological systems that may well exceed the ability of these systems to cope with, or adapt to, the changes that are being imposed. An example of this concerns the implications of human population growth. A necessary, although not sufficient, condition for the human population to live sustainability is that consumption of the Earth's $K_{\mathrm{NR}}$ needs to remain within its regenerative capacity - effectively living off $\mathrm{K}_{\mathrm{NR}}$ 'interest' rather than depleting capital (Footprint Network, 2010; Kitzes, 2007). The current human population is using $\mathrm{K}_{\mathrm{NR}}$ well in excess of its regenerative capacity, with this position of overshoot evident from at least 1980, with the rate of overshoot increasing and no signs evident of a reversal of this trend (Clifton, 2010c; Footprint Network, 2010). Within this context, a substantial portion of the current population is not having even vital physical needs met let alone what might be required to ensure flourishing lives for all (Bell, 2009; Rees, 2008). The key point to be made here is that it is not yet known if all members of the current human population, let alone what the population may grow to over coming years, are able to live flourishing lives within the limits of the Earth's $\mathrm{K}_{\mathrm{NR}}$ regenerative capacity. The mix of population and consumption is currently running ahead of sustainability criteria, with the implications masked by liquidation of the $\mathrm{K}_{\mathrm{NR}}$ capital base to support current lifestyles. Reformism's response to this problem is not one of seeking to reduce population numbers (in some cases, mostly in developed nations, action is instead being taken to prevent population reduction (Ehrlich \& Ehrlich, 2008; UN, 2008)) or to slow or cease consumptive-based economic growth - these two pressure sources on $\mathrm{K}_{\mathrm{NR}}$ use and the rates of change they impose remain in place. To pull total $\mathrm{K}_{\mathrm{NR}}$ consumption within sustainable limits, the focus of Reformism is instead on the deployment of technology solutions, which itself imposes additional rate of change pressures on socio-ecological systems.

In summary, Reformism's focus on the maximisation of human activity, and the issues that flow from this, pose substantial problems from a resilience perspective. Unlike the weak-anthropocentric vs. ecocentric issues discussed in section 6.1 where resilience concerns are more matters of the likelihood of errors in human decision making, the very nature of Reformism's maximisation and optimisation strategies gives rise to resilience eroding outcomes. In this sense, the more aggressively some aspects of the Reformist agenda are pursued - more global economic growth, greater optimisation of $\mathrm{K}_{\mathrm{NR}}$ productivity, rapid development and deployment of new technologies - the less resilient socio-ecological systems become. In this sense, Reformism is self-defeating.

6.2.2 Counter claims

Three main counter claims to the above arguments that will be addressed here concern: (a) the need for economic growth, (b) issues relating to population reduction, and (c) the need for, and benefits of, technology.

First, Reformism claims that continued economic growth is necessary for many reasons including generating employment opportunities, improving human wellbeing through the provision of goods and services to meet human needs and wants, and generating wealth to overcome poverty and to protect the environment (Hart, 2007; 
WBCSD, 2008; WCED, 1987). A steady-state economy as advocated by the Transformational-approach (SWT item 5.5) is, in this view, harmful to human wellbeing as it undermines all of these growth-based benefits with an overall result of broad-scale human hardship and suffering (Jackson, 2009).

Next, is a set of arguments in support of the Reformist population approach, and against that advocated by the Transformational-approach of reducing the human population as part of a set of strategies to reduce the scale of human impact on the Earth. These arguments include: (a) the negative consequences for economic growth a reducing population will cause (Ehrlich \& Ehrlich, 2008; Engelman, 2008), (b) the social hardships from an aging demographic profile that will result from a below-replacement fertility rate during the population reduction phase (Ehrlich \& Ehrlich, 2008; Engelman, 2008), and (c) the potential violation of the rights people have to choose their own family size (Hopfenberg \& Pimentel, 2001). Collectively these all point, so the claim goes, to a reduction in human wellbeing from pursuing the Transformational population narrative.

Third, is the issue of technology. A useful model for clarifying the importance of technology for both the Reformist and Transformational approaches is the I=PAT formulation (Chertow, 2000; Holdren et al., 1995).

$\mathrm{I}=\mathrm{PAT}$ presents human impact on the environment 'I', as a function of:

Population,

Affluence, as consumption/production per capita, and

Technology, as the environmental impact per unit of consumption/production.

Reformism seeks global population stability ('P'), strong global economic growth ('A'), and relies on technology ('T') to offset the impacts of ' $\mathrm{P}+\mathrm{A}$ ' to keep 'I' within critical ecological limits. The Transformational-approach on the other hand seeks to specifically restrict 'I' such that humans live well within ecological limits, and all of 'PAT' are addressed to ensure these limits on 'I' are not breached. Technology is also important for Reformism as a result of the important role the business sector plays in furthering the Reformist agenda (SWT item 4.2 and 5.5) where, as one Reformist advocate puts it "population and consumption are societal issues, [but] technology is the business of business" (Hart, 2007, p. 32).

For each of these three arguments, the key point of relevance for this current discussion is that they all argue in favour of continuing strategies claimed to further human wellbeing that are necessarily required by the current dominant economic system on which Reformism is based. Although they may be necessary to maintain this current system, they are not necessary for all economic systems (Cato, 2009; Jackson, 2009). This manner of defending the need to continue these key Reformist strategies does nothing to address the underlying socio-ecological-resilience concerns Reformism presents, and instead turns the focus on maintaining the socio-economic system (i.e., the means), rather than the desired flourishing-of-life goal (i.e., the ends). This is the point Transformational advocates make, by proposing that there are many ways in which human wellbeing can be progressed that do not carry the same resilience eroding problems inherent within Reformism's economic growth model. For the Transformational view, the focus is on the ends, with the means open to whatever restructuring is needed to ensure the primary sustainable-world goal is achieved. This leads to the third of the major themes considered in this paper - options.

\subsection{Options}

The final major theme that will be considered has to do with the options open to society to progress the achievement of a sustainable-world.

As evident from the I=PAT representations of the Reformist and Transformational approaches (see section 6.2.2 (above)), Reformism places constraints on the degree of social change it is willing to tolerate in order to see a sustainable-world achieved. For Reformism, what is needed are reforms to the current dominant socio-economic system to make it more green and just - in effect, making changes at the margin but maintaining the underlying principles on which this dominant model is based (Cato, 2009; Fox, 2003; Handmer \& Dovers, 1996; Williams \& Millington, 2004). In short, for Reformism, any strategy to progress a sustainable-world is acceptable so long as it fits within a green-and-just version of the current neo-liberal economic agenda.

From a socio-ecological-resilience perspective, this approach is concerning. It has the effect of making the ends (i.e. flourishing lives in terms of the primary sustainable-world goal), subordinate to the means (i.e. maintaining the current dominant socio-economic system), as opposed to the ends directing the means (Handmer \& Dovers, 1996). Resilience in this respect becomes one of resistance to socio-economic system change other than change at the margin (i.e., is of the engineering-resilience form), and requiring the primary sustainable-world goal to be achieved within these constraints. Within the socio-ecological-resilience context, this is a nonsense approach - it cuts right across the core principle of adaptive capacity, and places substantial constraints on society's options in addressing the challenges it may face (i.e., limits society's response diversity). Rather than presenting a coherent approach to progressing a sustainable-world, Reformism is more likely to ultimately see pressures build that force change by way of substantial socio-ecological-system restructure in ways that may be far from desirable (Handmer \& Dovers, 1996; Meadows, Randers, \& Meadows, 2004).

This limitation-of-options characteristic of Reformism is aggravated as a result of Reformism not only being the current dominant sustainable-world approach, but also being dominant to the exclusion of alternate narratives - 
to be heard in political and business domains, any proposals to progress a sustainable-world must fit the Reformist view (Dauvergne, 2008; Gould, Pellow, \& Schnaiberg, 2008; Handmer \& Dovers, 1996; Kallio, Nordberg, \& Ahonen, 2007). This is not surprising, as Reformism has achieved it dominance from it being espoused by the key power centres of society - business and government (see section 2.5 (above)), and is focused on maintaining the core elements of the economic system which these same power-centres advocate. Opening the door to alternate socio-economic models, as does the Transformational-approach, poses substantial threats to the self-interest of those who benefit from maintaining this current dominant economic system (Dauvergne, 2008; Kempf, 2008). From a socio-ecological-resilience perspective however, the continued pursuit of Reformism, to the exclusion of alternates, undermines society's resilience by reducing its adaptive capacity that is, as a result of it removing from social experience alternates to the one globally dominant core model, it narrows the range of socio-economic system states over which society can effectively function. Robinson (2004) makes this point in discussing the need for a society that is facing fundamental change to have "an alternative to the existing order that is viable and that is seen as viable and preferable by a majority of society" (p. 172). If, however, pursuing the Reformist-approach fails to deliver needed sustainable-world outcomes, as the broad resilience critique of the Reformist and Transformational approaches suggest is likely to be the case, then the dominance of Reformism to the exclusion of alternate narratives creates the very problem to which Robinson alludes.

\section{Discussion and conclusion}

\subsection{Summation}

This paper has presented, as Appendix 2 and the discussion in section 6 (above), a socio-ecological-resilience critique of the two main sustainable-world approaches evident in the literature - the Reformist and Transformational approaches. Reformism has been shown to be problematic from a resilience perspective in three main ways.

First, as evident from the weak-anthropocentric vs. ecocentric discussion in section 6.1, pursuit of the Reformist-approach exposes human decision making to greater risks of error that may harm human and ecological wellbeing than is evident for the Transformational-approach. The weak-anthropocentric vs ecocentric issue is of particular relevance in this context as its implications flow throughout the SWT and influence most of the broader set of dimensions that give meaning to the Reformist and Transformational narratives. Although it is possible to imagine a form of weak-anthropocentrism where the risks arising from incomplete human knowledge and cultural myopia are managed such that a sustainable-world does come to pass, Reformism, as it is currently constructed, imposes many constraints within which management of these risks needs to occur. The Transformational-approach is, in this respect, a preferable sustainable-world approach in socio-ecological-resilience terms. Its ecocentric ethic presents greater functional and response diversity in human decision making to protect Nature and respond to problems that arise, reducing the risks of harms to ecosystems that flow through to also harm human wellbeing.

The second key concern with Reformism, as reviewed in section 6.2, relates to its maximisation and optimisation strategies. Strategies such as a commitment to strong and continuous consumptive-based economic growth, maximising the human population, and optimising natural resource productivity, actively erode the resilience of socio-ecological-systems. The implications of this are substantial. What it means is that the Reformist-approach is, in a number of key respects, inherently self-defeating, where any appearance of purposeful action and wellbeing gains are transitory. Ultimately the erosion of socio-ecological-system resilience will take its toll leading to systems restructure with, most likely, very undesirable consequences. Alternately, the Transformational-approach is specifically focused on a smaller human scale, maintaining plenty of spare capacity and redundancy in socio-ecological-systems, and reducing human-induced rates of change on these systems to limit the risks of change outpacing feedback mechanism. In these respects, the Transformation-approach is preferable in socio-ecological-resilience terms.

The third key concern, as discussed in section 6.3 , is that by limiting solutions to progressing a sustainable-world to those consistent with the current dominant economic model of global GDP growth, globalisation, free-trade, and the consumption of market-produced goods and services (effectively, a green-and-just version of the current neo-liberal agenda), Reformism acts as a barrier to the uptake of other solutions that may well be needed to see a sustainable-world come about. This is particularly concerning in the light of the higher risk and self-defeating nature of Reformism as discussed above. The effect is that resilience for Reformism follows the engineering-resilience model of resistance to change - all efforts to progress the primary sustainable-world goal must take place within a pre-determined economic idealism which is not open to change other than at the margin to address green-and-just issues. The Transformational-approach places the focus on the sustainable-world goal and is tolerant of fundamental change to social systems and institutions to see this goal achieved (SWT item 5.4). In this respect, it allows society to adapt to changing circumstances in whatever ways might be necessary to ensure a sustainable-world is achieved and maintained.

Of these three main areas of concern regarding Reformism's merits as a credible sustainable-world approach, it is this barrier to alternates that is possibly the most troublesome. Sustainability is a human social issue - current 
problems are human caused, and humans are the only entity able to think about sustainable-world issues and do something about them (SWT items 4.1 and 4.2). In this respect, transitioning to a sustainable-world is first and foremost a social transition issue, dependent on the extent of society's adaptive capacity. Unless Reformism's intolerance of social-systems change beyond the margin can be overcome, then successful transition to a sustainable-world will remain elusive.

\subsection{Contribution, limitations, future research}

Although there is a growing body of literature that considers sustainable-world issues from a socio-ecological-resilience perspective, its application across the broad spectrum of dimensions that give meaning to a sustainable-world is currently quite limited. This paper has sought to progress this area of enquiry by considering the content of the SWT in socio-ecological-resilience terms. In particular, it has sought to progress application of socio-ecological-resilience principles to the social-systems setting, which is currently a poorly developed area.

The extent to which this paper has been able to present the resilience issues relevant to a sustainable-world is, however, quite limited. The subject matter is very broad, with the summary findings shown in Appendix 2 necessarily brief, and the review in section 6 (above) able to cover only a narrow range of issues worthy of detailed exploration. Beyond this, a key limitation to the findings is that the critique of the SWT content is based on a set of socio-ecological-resilience criteria (as per Appendix 1) that have been sourced from literature dealing with socio-ecological-resilience issues within the context of ecological, socio-ecological, social, and economic systems, plus, more generally, complex-adaptive-systems. The key point is that application of socio-ecological-resilience to the sustainable-world context, in particular to social-systems, is an emerging field of enquiry. Although some socio-ecological-resilience issues, especially in the ecosystems setting, are supported by comprehensive research (e.g., see Gunderson \& Holling (2002), Walker \& Salt (2006), and Gunderson, Allen, $\&$ Holliday (2010b)), application in this paper of general complex-adaptive-systems concepts (as per Appendix 1) to specific sustainable-world dimensions (as per Appendix 2), is, to a degree, a theoretical application not necessarily supported by research specific to each of the sustainable-world dimensions in question. Further research in this area would be very beneficial.

Ultimately though, a sustainable-world is a social transition issue. Further research as to how society might go about undertaking an orderly and peaceful transition to a sustainable-world is of significant importance. Such research is, however, only as good as its outcomes. If, as has been alluded to above, barriers to the implementation of needed change to progress a sustainable-world are to a material degree based in the defence of an economic idealism by the core power centres of society, then, as is evident with the current wrestle over the reality, or cause, or severity, of global warming, and embarking on a path of corrective action (Hamilton, 2007; Hoggan, 2009; Pearse, 2007), many challenges lie ahead in seeing needed change come about.

\section{References}

Adams, W. M. (2006). The Future of Sustainability: Re-thinking Environment and Development in the Twenty-first Century. The World Conservation Union.

Adger, W. N. (2006). Vulnerability. Global Environmental Change, 16(3), 268-281.

Adger, W. N. (2007). Ecological and Social Resilience. In G. Atkinson, S. Dietz \& E. Neumayer (Eds.), Handbook of Sustainable Development (pp. 78-90). Cheltenham, UK: Edward Elgar Publishing Limited.

Adu-Febiri, F. (2006). The Destiny of Cultural Diversity in a Globalized World. Review of Human Factor Studies, 12(1), 30-64.

Banerjee, S. B., \& Linstead, S. A. (2001). Globalization, Multiculturalism and Other Fictions: Colonialism for the New Millennium? Organization, 8(4), 683.

Beder, S. (2006). Environmental Principles and Policies: An Interdisciplinary Introduction. London: Earthscan.

Bell, M. M. (2009). An Invitation to Environmental Sociology. California, USA: Pine Forage Press.

Blewitt, J. (2008). Understanding Sustainable Development. London: Earthscan.

Brown, L. (1995). Ecopsychology and the Environmental Revolution. In T. Roszak, M. E. Gomes \& A. D. Kanner (Eds.), Ecopsychology: Restoring the Earth, Healing the Mind (pp. xiiv-xvi). Berkley, California: Sierra Club Books.

Brown, L. (2008). Plan B 3.0. New York: W. W. Norton \& Company Inc.

Castro, C. J. (2004). Sustainable Development. Organization \& Environment, 17(2), 195-225.

Cato, M. S. (2009). Green Economics. London: Earthscan.

Chertow, M. R. (2000). The IPAT Equation and Its Variants. Journal of Industrial Ecology, 4(4), 13.

Clifton, D. (2010a). Representing a Sustainable World - A Typology Approach. Journal of Sustainable Development, 3(2), 40-57.

Clifton, D. (2010b). Sustainability and Government - A Case Study of the South Australian Government. Journal of Environment and Ecology, 1(1), 1-27.

Clifton, D. (2010c). A Sustainable World - an Ecological Footprint and I=PAT Perspective. Journal of the Asia-Pacific Centre for Environmental Accountability, 16(2), 3-26. 
Clifton, D., \& Amran, A. (2010). The Stakeholder Approach: A Sustainability Perspective. Journal of Business Ethics.

CODP. (2003). The Concise Oxford Dictionary of Politics. Oxford: Oxford University Press.

Conn, S. A. (1995). When the Earth Hurts, Who Responds? In T. Roszak, M. E. Gomes \& A. D. Kanner (Eds.), Ecopsychology: Restoring the Earth, Healing the Mind (pp. 157-171). Berkley, California: Sierra Club Books.

Cranor, C. F. (2004). Toward Understanding Aspects of the Precautionary Principle. Journal of Medicine \& Philosophy, 29(3), 259-279.

Daly, H., \& Farley, J. (2004). Ecological Economics: Principles and Applications. Washington: Island Press.

Daly, H. E. (1996). Beyond Growth: The Economics of Sustainable Development. Boston: Beacon Press.

Daly, H. E. (1999). Ecological Economics and the Ecology of Economics. Cheltenham, UK.: Edward Elgar.

Dauvergne, P. (2008). The Shadows of Consumption. Cambridge, MA, USA: MIT Press.

Davion, V. (2004). The Earth Charter and Militarism: An Ecological Feminist Analysis. Worldviews: Environment Culture Religion, 8(1), 112-125.

Dawe, N. K., \& Ryan, K. L. (2003). The Faulty Three-Legged-Stool Model of Sustainable Development. Conservation Biology, 17(5), 1458-1460.

Diesendorf, M. (1997). Principles of Ecological Sustainability. In M. Diesendorf \& C. Hamilton (Eds.), Human Ecology, Human Economy (pp. 64-97). Sydney: Allen \& Unwin.

Dietz, S., \& Neumayer, E. (2007). Weak and Strong Sustainability in the SEEA: Concepts and Measurement. Ecological Economics, 61(4), 617-626.

Dobson, A. (1996). Environmental Sustainabilities: An Analysis and a Typology. Environmental Politics, 5(3), 401-428.

Dorman, P. (2005). Evolving Knowledge and the Precautionary Principle. Ecological Economics, 53(2), 169-176.

Dudgeon, R. C., \& Berkes, F. (2003). Local Understandings of the Land: Traditional Ecological Knowledge and Indigenous Knowledge. In H. Selin (Ed.), Nature Across Cultures (pp. 75-96). Dordrecht, Netherlands: Kluwer Academic Publishers.

Ehrlich, P. R., \& Ehrlich, A. H. (Eds.). (2008). The Dominant Animal. Washington DC: Island Press.

Engelman, R. (2008). More: Population, Nature, and What Women Want. Washington DC.: Island Press.

Escobar, A. (1995). Encountering Development: The Making and Unmaking of the Third World. New Jersey: Princeton University Press.

Folke, C. (2006). Resilience: The Emergence of a Perspective for Social-Ecological Systems Analyses. Global Environmental Change, 16, 253-267.

Folke, C., Carpenter, S., Elmqvist, T., Gunderson, L., Holling, C. S., Walker, B., et al. (2002). Resilience and Sustainable Development: Building Adaptive Capacity in a World of Transformations. Stockholm, Sweden: The Environmental Advisory Council to the Swedish Government: Scientific Background Paper on Resilience for the process of The World Summit on Sustainable Development.

Folke, C., Carpenter, S., Walker, B., Scheffer, M., Elmqvist, T., Gunderson, L., et al. (2010). Regime Shifts, Resilience, and Biodiversity in Ecosystem Management (reproduced article from Annual Review Ecology Evolution Systematics, 2004, v 35, pp 557-581). In L. Gunderson, C. R. Allen \& C. Holliday (Eds.), Foundations of Ecological Resilience. Washington DC: Island Press.

Footprint Network. (2010). Ecological Footprint: Footprint Network web site at http://www.footprintnetwork.org/.

Fox, W. (1995). Toward a Transpersonal Ecology. New York: State University of New York Press.

Fox, W. (2003). Deep Ecology: A New Philosophy of Our Time (reproduced from "The Ecologist" 1984). In A. Light \& H. Rolston (Eds.), Environmental Ethics (pp. 252-261). Oxford, UK.: Blackwell Publishers Ltd.

Gallopin, G. (2003). A Systems Approach to Sustainability and Sustainable Development: United Nations Economic Commission for Latin America and the Caribbean: Sustainability Assessment in Latin America and the Caribbean project.

Gallopin, G. (2006). Linkages Between Vulnerability, Resilience, and Adaptive Capacity. Global Environmental Change, 16, 293-303.

Gibbs, D., \& Krueger, R. (2005). Exploring local capacities for sustainable development. Geoforum, 36(4), 407-409.

Gould, K. A., \& Lewis, T. L. (2009). The Paradoxes of Sustainable Development. In K. A. Gould \& T. L. Lewis (Eds.), Twenty Lessons in Environmental Sociology (pp. 269-289). New York: Oxford University Press.

Gould, K. A., Pellow, D. N., \& Schnaiberg, A. (2008). The Treadmill of Production. Boulder, Colorado USA: Paradigm Publishers.

Gunderson, L., Allen, C. R., \& Holliday, C. (2010a). Commentrary on Part One Articles. In L. Gunderson, C. R. Allen \& C. Holliday (Eds.), Foundations of Ecological Resilience. Washington DC: Island Press. 
Gunderson, L., Allen, C. R., \& Holliday, C. (Eds.). (2010b). Foundations of Ecological Resilience. Washington DC: Island Press.

Gunderson, L., \& Holling, C. S. (Eds.). (2002). Panarchy: Understanding Transformations in Human and Natural Systems. Washington DC: Island Press.

Hamilton, C. (2007). Scorcher: The Dirty Politics of Climate Change. Melbourne: Black Inc.

Handmer, J. W., \& Dovers, S. R. (1996). A Typology of Resilience: Rethinking Institutions for Sustainable Development. Industrial and Environmental Crisis Quarterly, 9(4), 482-511.

Hanna, M. D. (1995). Environmentally Responsible Managerial Behavior: Is Ecocentrism a Prerequisite? Academy of Management Review, 20(4), 796-799.

Hargrove, E. C. (2003). Weak Anthropocentric Intrinsic Value (reproduced from "The Monist", 1992). In A. Light \& H. Rolston (Eds.), Environmental Ethics (pp. 175-190). Oxford, UK.: Blackwell Publishers Ltd.

Hart, S. L. (2007). Capitalism at the Crossroads (2nd ed.). New Jersey: Pearson Education.

Hoggan, J. (2009). Climate Cover-Up. Vancouver: Greystone Books.

Holdren, J. P., Daily, G. C., \& Ehrlich, P. R. (1995). The Meaning of Sustainability: Biogeophysical Aspects. Washington DC: United Nations University and The World Bank.

Holland, A. (1997). Substitutability. In J. Foster (Ed.), Valuing Nature? Ethics, Economics and the Environment (pp. 119-134). London: Routledge.

Holling, C. S. (1996). Engineering Resilience versus Ecological Resilience. In P. C. Schulze (Ed.), Engineering Within Ecological Constraints (pp. 31-44). Washington, D.C.: National Academy Press.

Hopfenberg, R., \& Pimentel, D. (2001). Human Population Numbers as a Function of Food Supply. Environment, Development and Sustainability, 3, 1-15.

Hughes, J. D. (2001). An Environmental History of the World. New York: Routledge.

IPCC. (2010). Intergovernmental Panel on Climate Change: Intergovernmental Panel on Climate Change at http://www.ipcc.ch/.

Jackson, T. (2009). Prosperity Without Growth. London: Earthscan.

Kallio, T. J., Nordberg, P., \& Ahonen, A. (2007). Rationalizing Sustainable Development - A Critical Treatise. Sustainable Development, 15(1), 41-51.

Kempf, H. (2008). How the Rich are Destroying the Earth. Devon, UK: Green Books.

Kitzes, J. (2007, 8-10 May 2007). A Research Agenda for Improving National Ecological Footprint Accounts. Paper presented at the International Ecological Footprint Conference: Stepping Up the Pace - New Developments in Ecological Footprint Methodology, Policy and Practice, Cardiff.

Light, A., \& Rolston, H. (2003). Introduction: Ethics and Environmental Ethics. In Environmental Ethics (pp. 1-11). Oxford, UK.: Blackwell Publishers Ltd.

Mander, J. (2003). Intrinsic Negative Effects of Economic Globalization on the Environment. In J. G. Speth (Ed.), Worlds Apart - Globalization and the Environment. Washington D.C.: Island Press.

Meadows, D. H. (1999). Leverage Points: Places to Intervene in a System: The Sustainability Institute.

Meadows, D. H., Meadows, D. L., Randers, J., \& Behrens, W. W. (1972). The Limits to Growth. New York: Universe Books.

Meadows, D. H., Randers, J., \& Meadows, D. (2004). Limits to Growth: The 30-Year Update. White River Junction: Chelsea Green Publishing Company.

Minteer, B. A. (Ed.). (2009). Nature in Common. Philadelphia: Temple University Press.

Naess, A. (1989). Ecology, Community and Lifestyle. Cambridge: Cambridge University Press.

Naess, A. (2005). The Basics of Deep Ecology. The Trumpeter, 21(1), 61-71.

Norton, B. G. (2003). Environmental Ethics and Weak Anthropocentrism (reproduced from "Environmental Ethics", 1984). In A. Light \& H. Rolston (Eds.), Environmental Ethics (pp. 163-174). Oxford, UK.: Blackwell Publishers Ltd.

O'Neill, J., Holland, A., \& Light, A. (2008). Environmental Values. Abingdon, UK: Routledge.

Orton, D. (1990). Sustainable Development: Expanded Environmental Destruction. Green Web Bulletin, 16.

Osorio, L. A., Lobato, M. O., \& Castillo, X. (2005). Debates on Sustainable Development: Towards a Holistic View of Reality. Environment, Development and Sustainability, 7, 501-518.

Palmer, C. (2003). An Overview of Environmental Ethics. In A. Light \& H. Rolston (Eds.), Environmental Ethics (pp. 15-37). Oxford, UK.: Blackwell Publishers Ltd.

Pearce, D., \& Atkinson, G. (1998). The Concept of Sustainable Development: An Evaluation of its Usefulness Ten Years After Brundtland: Centre for Social and Economic Research on the Global Environment, University College London and University of East Anglia: Working Paper PA 98-02.

Pearse, G. (2007). High \& Dry. Camberwell, Victoria: Penguin Group (Australia).

Perrings, C. (2006). Resilience and Sustainable Development. Environment and Development Economics, 11, 417-427. 
Peterson, G., Allen, C. R., \& Holling, C. S. (1998). Ecological Resilience, Biodiversity, and Scale. Ecosystems, 1, 6-18.

Porritt, J. (2005). Capitalism As If The World Matters. London: Earthscan.

Princen, T. (2005). The Logic of Sufficiency. Cambridge MA, USA: MIT Press.

Rees, W. E. (2008). Human Nature, Eco-footprints and Environmental Injustice. Local Environment, 13(8), 685-701.

Rees, W. E., \& Westra, L. (2003). When Consumption Does Violence: Can There be Sustainability and Environmental Justice in a Resource-limited World? In J. Agyeman, R. D. Bullard \& B. Evans (Eds.), Just Sustainabilities: Development in an Unequal World. London: Earthscan.

Robinson, J. (2004). Squaring the Circle? Some Thoughts on the Idea of Sustainable Development. Ecological Economics, 48, 369-384.

Robinson, W. I. (2004). A Theory of Global Capitalism. Baltimore, US: The John Hopkins University Press.

Rockström, J., Steffen, W., Noone, K., Persson, A., Chapin, F. S., Lambin, E. F., et al. (2009). A Safe Operating Space for Humanity. Nature, Vol 461(24), 472-475.

Rodman, J. (1995). Four Forms of Ecological Consciousness Reconsidered. In G. Sessions (Ed.), Deep Ecology for the 21st Century. Boston, USA: Shambhala Publications Inc.

Schoon, M. L. (2005). A Short Historical Overview of the Concepts of Resilience, Vulnerability, and Adaptation: Workshop in Political Theory and Policy Analysis, Indiana University, Working Paper W05-4, 29 January 2005.

Shiva, V. (2000). Stolen Harvest. Cambridge, MA: South End Press.

Shiva, V. (2005). Earth Democracy. Cambridge, Massachusetts: South End Press.

Speth, J. G., \& Haas, P. M. (2006). Global Environmental Governance. Washington DC: Island Press.

Taylor, P. (1989). Respect for Nature. Princeton: Princeton University Press.

Taylor, P. (2003). The Ethics of Respect for Nature (reproduced from "Environmental Ethics 3", 1981). In A. Light \& H. Rolston (Eds.), Environmental Ethics (pp. 74-84). Oxford, UK.: Blackwell Publishers Ltd.

Tuler, S., Agyeman, J., da Silva, P. P., LoRusso, K. R., \& Kay, R. (2008). Assessing Vulnerabilities: Integrating Information about Driving Forces that Affect Risks and Resilience in Fishing Communities. Human Ecology Review, 15(2), 171-184.

Turner, K. R. (1992). Speculations on Weak and Strong Sustainability: Centre for Social and Economic Research on the Global Environment University of East Anglia and University College London, Working Paper GEC 92-26.

UHK. (2010). Critical Thinking Wed: The Philosophy Department, The University of Hong Kong, an http://philosophy.hku.hk/think/.

UN. (1992a). Rio Declaration on Environment and Development.

UN. (1992b). United Nations Framework Convention on Climate Change: United Nations.

UN. (2008). World Population Policies 2007. New York: United Nations: Department of Economic and Social Affairs - Population Division.

UNEP. (2007). Global Environmental Outlook 4. Nairobi, Kenya.: United Nations Environmental Programme.

UNEP. (2009). Climate Change Science Compendium. Nairobi: United Nations Environment Programme.

UNESCO. (2001). Universal Declaration on Cultural Diversity: United Nations Educational, Scientific and Cultural Organisation.

Wackernagel, M., Onisto, L., Bello, P., Linares, A. C., Falfan, I. S., Garcia, J. M., et al. (1999). National Natural Capital Accounting with the Ecological Footprint Concept. Ecological Economics, 29, 375-390.

Wackernagel, M., \& Rees, W. E. (1997). Perceptual and Structural Barriers to Investing in Natural Capital: Economics From an Ecological Footprint Perspective. Ecological Economics, 20(1), 3-24.

Walker, B., Gunderson, L., Kinzig, A., Folke, C., Carpenter, S., \& Schultz, L. (2006). A Handful of Heuristics and Some Propositions for Understanding Resilience in Social-Ecological Systems. In B. H. Walker, J. M. Anderies, K. A. P. \& P. Ryan (Eds.), Exploring Resilience in Socio-Ecological Systems, Chapter 2. Collingwood, Australia: CSIRO Publishing.

Walker, B., \& Salt, D. (2006). Resilience Thinking: Sustaining Ecosystems and People in a Changing World. Washington DC: Island Press.

WBCSD. (2008). The World Business Council for Sustainable Development - web site. Retrieved 16 June, 2008, from

http://www.wbcsd.ch/templates/TemplateWBCSD5/layout.asp?type=p\&MenuId=Njk\&doOpen=1\&ClickMenu= LeftMenu

WCED. (1987). Our Common Future: World Commission on Environment and Development. Oxford: Oxford University Press.

Williams, C. C., \& Millington, A. C. (2004). The Diverse and Contested Meanings of Sustainable Development. Geographical Journal, 170(2), 99-104. 
Appendix 1: Socio-ecological-resilience in complex-adaptive-systems (CASs)

\begin{tabular}{|c|c|}
\hline Characteristic & Description \\
\hline $\begin{array}{l}\text { (a) Adaptability / } \\
\text { adaptive-capacity }\end{array}$ & $\begin{array}{l}\text { Description: The ability or capacity of a CAS to: (a) modify its characteristics or behaviour to better cope } \\
\text { with existing or anticipated disturbance and move to a less vulnerable condition, and (b) expand the } \\
\text { range over which it can cope, so it can continue to function despite disturbance. } \\
\text { Resilience relationship: Increased adaptability reduces vulnerability and increases resilience. }\end{array}$ \\
\hline (b) Diversity & $\begin{array}{l}\text { Description: The extent to which a CAS is made up of different things by way of form and function. } \\
\text { Resilience relationship: Greater system diversity, in particular functional diversity (different system parts } \\
\text { doing different things, or doing the same thing in different ways), and response diversity (different } \\
\text { system parts responding to disturbance in different ways), increases resilience. }\end{array}$ \\
\hline (c) Exposure & $\begin{array}{l}\text { Description: The extent to which a CAS is open to the influence of disturbance. } \\
\text { Resilience relationship: Greater exposure increases vulnerability and reduces resilience. Is closely linked } \\
\text { to sensitivity as exposure is increasingly problematic from a resilience perspective the greater the } \\
\text { sensitivity of the system to the disturbance to which it is being exposed. }\end{array}$ \\
\hline (d) Integrity & $\begin{array}{l}\text { Description: The ability of a CAS to maintain its normal functions, evolutionary potential, adaptive } \\
\text { capacity, and ability to self-organise. Is linked to diversity - greater diversity enhances integrity. } \\
\text { Resilience relationship: Greater integrity reduces vulnerability and increases resilience. }\end{array}$ \\
\hline (e) Modularity & $\begin{array}{l}\text { Description: The manner in which a CAS's components are linked and compartmentalised. } \\
\text { Resilience relationship: Resilient systems need to maintain some degree of modularity (i.e., systems } \\
\text { sub-groups are highly linked internally but only loosely connected to each other) to limit the extent to } \\
\text { which shocks travel through the system. Some level of interconnectedness is normal. Excessive } \\
\text { interconnectedness increases vulnerability and reduces resilience. }\end{array}$ \\
\hline (f) Rate of change & $\begin{array}{l}\text { Description: The rate of change that a CAS undergoes. Is linked to: (a) feedback mechanisms where change } \\
\text { can outstrip the pace of feedback on the consequences of change, and (b) adaptive capacity where } \\
\text { change can occur at a rate faster than which system elements can cope. } \\
\text { Resilience relationship: A slower rate of change in environmental variables increases resilience. }\end{array}$ \\
\hline (g) Redundancy & $\begin{array}{l}\text { Description: Refers to CAS functional and response diversity - the greater this diversity, the greater a } \\
\text { system's redundancy. (Note: This differs from engineering redundancy which focuses on maximum } \\
\text { efficiency through the removal of duplication, with redundancy considered in terms of back-up systems } \\
\text { to take over in the event of main systems failure). } \\
\text { Resilience relationship: Greater redundancy reduces vulnerability and increases resilience. }\end{array}$ \\
\hline (h) Sensitivity & $\begin{array}{l}\text { Description: The degree to which a CAS is modified or affected when exposed to disturbance. The more } \\
\text { sensitive a system, the greater the level of impact it experiences from disturbance. } \\
\text { Resilience relationship: Greater sensitivity increases vulnerability and reduces resilience. Is closely linked } \\
\text { to exposure where the greater the sensitivity to a particular disturbance, the less exposure to the } \\
\text { disturbance a system can tolerate without risk of harm. }\end{array}$ \\
\hline (i) Spare capacity & $\begin{array}{l}\text { Description: The distance from thresholds - greater distance increases spare capacity. } \\
\text { Resilience relationship: Greater spare capacity increases the magnitude of disturbance a CAS can } \\
\text { experience without flipping into an alternate regime, and hence increases resilience. }\end{array}$ \\
\hline (j) Thresholds & $\begin{array}{l}\text { Description: Boundaries which, if crossed, see a system move from one regime to another, although where } \\
\text { these thresholds lie is often unknown. Resilience in the CAS context is about ensuring thresholds are not } \\
\text { crossed that, if done, would see the system move into an undesirable regime. } \\
\text { Resilience relationship: The further away from thresholds a CAS is, the more resilient it is. }\end{array}$ \\
\hline (k) Vulnerability & $\begin{array}{l}\text { Description: The extent to which a CAS is susceptible to harm through being unable to cope with } \\
\text { disturbance to which it is exposed. } \\
\text { Resilience relationship: A loss of resilience results in a CAS becoming more vulnerable to change from a } \\
\text { disturbance that could otherwise have been absorbed. Change in a resilient system can present } \\
\text { opportunities for renewal, innovation, and creativity. In a vulnerable system change is more likely to be } \\
\text { harmful to systems goal achievement. }\end{array}$ \\
\hline
\end{tabular}

Key data sources: Adger (2006; 2007), Diesendorf (1997), Folke et al (2002), Gallopin (2006), Handmer \& Dovers (1996), Meadows, (1999), Meadows et al. (2004), Peterson (1998), Perrings (2006), Schoon (2005), Tuler, Agyeman, da Silva, LoRusso, \& Kay (2008), Walker \& Salt (2006), and Walker et al. (2006). 
Appendix 2: Sustainable-world Typology - Socio-ecological-resilience critique

1. Dimensions: Sustainable-world ('SW') Dimensions represented in the Sustainable-world typology ('SWT') are:

\begin{tabular}{|l|l|}
\hline Item & SW-Dimension description \\
\hline $\mathbf{1 .}$ & Primary Sustainable-world Goal \\
\hline 1.1. & Primary Goal \\
\hline 1.2. & Primary Goal area of focus \\
\hline $\mathbf{2 .}$ & Space and time \\
\hline $\mathbf{3 .}$ & Satisfaction of interests \\
\hline 3.1. & Interests: Scope \\
\hline 3.2 .1$. & Interests: Mechanism (human) \\
\hline 3.2 .2$. & Interests: Mechanism (non-human) \\
\hline 3.3 .1$. & Interests: Population (human) \\
\hline 3.3 .2$. & Interests: Population (non-human) \\
\hline $\mathbf{4 .}$ & Responsibility \\
\hline 4.1. & Cause \\
\hline 4.2. & Remedy \\
\hline
\end{tabular}

\begin{tabular}{|l|l|}
\hline Item & SW-Dimension description \\
\hline $\mathbf{5 .}$ & General principles and concepts \\
\hline 5.1. & Modelling a SW - the 3-Element Model \\
\hline 5.2. & Justice \\
\hline 5.3. & Human Interests - Resources \\
\hline 5.4. & Risk and Precaution \\
\hline 5.5. & Growth and Development \\
\hline 5.6. & Diversity \\
\hline 5.6 .1$. & Biodiversity \\
\hline 5.6 .2$. & Cultural diversity \\
\hline 5.7. & Security \\
\hline
\end{tabular}

2. Acronyms

\begin{tabular}{|ll|ll|ll|}
\hline $\mathrm{CAS}$ & Complex adaptive system & $\mathrm{K}_{\mathrm{NR}}$ & Renewable natural capital & $\mathrm{SW}$ & Sustainable world \\
\hline EcoC & Ecocentrism & $\mathrm{K}_{\mathrm{HF}}$ & Human forms of capital & $\mathrm{TA}$ & Transformational approach \\
\hline $\mathrm{GMO}$ & Genetically modified organism & $\mathrm{RA}$ & Reformist approach & WAnth & Weak anthropocentrism \\
\hline IntraG & Intragenerational & $\mathrm{SER}$ & Socio-ecological resilience & WMD & Weapons of mass destruction \\
\hline InterG & Intergenerational & SES & Socio-ecological system & WSust & Weak sustainability \\
\hline $\mathrm{K}_{\mathrm{N}}$ & Natural capital & SSust & Strong sustainability & &
\end{tabular}

3. The Sustainable-world Typology

\section{Primary Sustainable-world Goal}

1.1. Primary Goal

(a) Definitional: The primary Sustainable-world goal is the flourishing of life over an indefinite time frame.

\section{(b) Socio-ecological resilience critique}

From a SW perspective, the 'maintenance of function' of which SER is concerned is: 'The continued meeting of the primary SW goal of flourishing life, incorporating both human and ecological wellbeing, and doing so regardless of what changes might occur in the socio-ecological systems from which this wellbeing is derived'.

\subsection{Primary Goal area of focus}

(a) Reformist: Weak anthropocentrism

What is to be sustained is the flourishing of human life through the satisfaction of human Fulfilment Interests ${ }^{\# 1}$ based on Considered Human Preferences ${ }^{\# 2}$.

The non-human world is only (or mostly) of instrumental value in meeting Considered Human Preferences.

(b) Transformational: Ecocentrism

What is to be sustained is the flourishing of human and non-human life through the satisfaction of Fulfilment Interests.

Both human and non-human interests given consideration - humans interests do not take automatic preference. 


\subsection{Primary Goal area of focus (continued)}

\section{(c) Socio-ecological resilience critique}

(i) The RA: WAnth: (a) places protection of Nature within the realm of identifiable human interests, the cultural context in which interests are determined (Light \& Rolston, 2003), and the limitations of human knowledge (Diesendorf, 1997); this exposes ecosystems to human decision making errors that are SER eroding (e.g., biodiversity loss, increasing ecosystem exposure to harm through the magnitude of imposed change, and imposing too fast a rate of change), and (b) supports human-Nature dualism (Palmer, 2003; Taylor, 2003) that can reduce identification with ecological damage, and lead to greater ecological harm and less motivation to resolve ecological problems (Conn, 1995).

(ii) The TA: EcoC: (a) sees the non-human world as having both instrumental value and value for its own sake, and focuses on both human and non-human interests, not one to the exclusion of the other (Fox, 1995; Rodman, 1995), (b) provides a basis for protecting Nature where no human interest is apparent (CODP, 2003; Light \& Rolston, 2003), and (c) rejects human-Natural dualism (Naess, 2005; Taylor, 1989). As such, it helps address the Wanth problems of incomplete knowledge, cultural myopia, and dualism, and increases functional diversity in human decision making to protect Nature, and response diversity as to how humans respond to ecosystem damage.

(iii) Conclusion: For this SWT item '1.2. Primary Goal area of focus':

The TA is a preferred SW approach in SER terms as it reduces the risks of error in: (a) human decision towards Nature, and

(b) in responding to ecological damage.

Notes:

\#1: Fulfilment Interests: are things that are conducive to the flourishing of something (a person, society, animal, etc).

\#2: Considered Human Preferences: are "any desire or need that a human individual would express after careful deliberation, including a judgment that the desire or need is consistent with a rationally adopted world view" (Norton, 2003, p. 164). In the SW context, these are preferences consistent with a rationally adopted SW view.

\#3: Felt Human Preferences: are "any desire or need of a human individual that can at least temporarily be sated by some specifiable experience of that individual" (Norton, 2003, p. 164)

\section{Space and time}

Definitional: A Sustainable-world is ultimately concerned with humans living sustainably at the global level over an indefinite time frame.

\section{Satisfaction of interests}

3.1. Interests: Scope: which needs (human and non-human) are to be met, and to what extent are they to be met?

(b) Reformist: Justice in meeting human needs and wants

Justice in meeting human Fulfilment Needs ${ }^{\# 4}$, then justice in meeting human wants ${ }^{\# 5}$.

Non-human species interest satisfaction based mostly, but not always, on their use in satisfying human interests.

(b) Transformational: Justice in meeting needs for all life

First, justice in meeting Fulfilment Needs for humans and non-human species, then justice in meeting human wants.

(c) Socio-ecological resilience critique

(i) The RA: is framed within the Wanth view as per SWT item 1.2.

(ii) The TA: is framed within the EcoC view as per SWT item 1.2.

(iii) Discussion points: From an SER perspective, the moral question as to the value of human vs non-human life, and which needs are to be met for human and non-human life, is not the issue at stake - SER is amoral (Walker \& Salt, 2006). The issue of relevance is the flow-on implications for human and ecological wellbeing. In this respect, similar issues apply as for SWT item 1.2.

(iv) Conclusion: For this SWT item '3.1. Interests: Scope':

The TA is preferred from a SER perspective due to its EcoC orientation.

Notes:

\#4: Fulfilment needs: are those things that must be satisfied in order for fulfilment interests to be met.

\#5: Human wants: are those things that go beyond fulfilment needs but are not conditional for a flourishing life.

\subsubsection{Interests: Mechanism (human): How are interests to be satisfied for humans?}

(a) Reformist: Green and equitable consumerism

Focus on consumption of goods and services produced and consumed in environmentally responsible and socially just (green-and-just) ways. Consumption that increases GDP for all of humanity is a fundamental social good.

(b) Transformational: Sufficiency and life experiences

Focus on non-material life experiences, with consumption of goods and services based on sufficiency criteria.

Increased consumption needs of the poor are important and achieved through redistribution not more growth. 


\subsubsection{Interests: Mechanism (human) (continued)}

\section{(c) Socio-ecological resilience critique}

(i) The RA: The focus on consumption: (a) maintains pressures on $\mathrm{K}_{\mathrm{NR}}$ use that are currently eroding ecosystem spare capacity and pushing ecosystems towards and beyond thresholds (Clifton, 2010c; Wackernagel et al., 1999), (b) increases social system sensitivity as disruptions to $\mathrm{K}_{\mathrm{N}}$ supply can impact adversely on human wellbeing where this wellbeing is primarily focused on consumptive satisfiers, (c) increases ecosystem exposure, as a focus on consumption requires consumptive processes to be maintained regardless of $\mathrm{K}_{\mathrm{N}}$ impacts, and (d) reduces social system adaptive capacity as options for pursuing human wellbeing are constrained within a consumptive paradigm and set of cultural norms.

Strategies to optimise the productivity-efficiency of the Earth's $K_{\mathrm{NR}}$ stocks to provided needed resource flows (SWT items 3.2.2, and 5.5) detracts from SER as it: (a) reduces ecosystem spare capacity, (b) simplifies landscapes resulting in reduced diversity, and (c) reduces the adaptive capacity of landscapes (Walker \& Salt, 2006).

(ii) The TA: The TA is more willing than the RA to pursue alternate approaches to human interests satisfaction that do not depend on consumption beyond a 'sufficiency' level. Non-material life satisfiers (e.g. cultural, spiritual, and psychological growth) are seen to be not subject to physical limits (Gallopin, 2003; Meadows, Meadows, Randers, \& Behrens, 1972) and in this respect, can be pursued without negative SES impacts. This: (a) increases society's response diversity by seeing humanity respond to ecological degradation in ways that directly address one of its core drivers - excessive $\mathrm{K}_{\mathrm{NR}}$ use - that the RA does not pursue in such a forceful way, and (b) increases society's functional diversity by providing alternate non-material means of achieving human wellbeing.

(iii) Conclusion: For this SWT item '3.2.1. Interests: Mechanism (human)':

The RA: (a) in some respects, supports strategies that are inherently SER eroding (i.e., optimisation of $\mathrm{K}_{\mathrm{NR}}$ productivity) and in this respect is self-defeating, and (b) incorporates some human behaviours (e.g. reduced diversity in furthering human-wellbeing) that are less supportive of SER than the TA.

The TA is a preferred SW approach in SER terms.

\subsubsection{Interests: Mechanism (non-human): How are interests to be satisfied for non-human life?}

(a) Reformist: Constrained to human parameters - Weak Anthropocentrism orientation

Non-human life is managed by humans mostly as natural resources for satisfaction of Considered Human Preferences.

Supportive of technology-focused agricultural practices, including the use of GMOs and other intensive technology based crop and animal production practices, if done in ways consistent with the green-and-just Reformist criteria.

(b) Transformational: Unconstrained flourishing - Ecocentrism orientation

Humans manage themselves rather than managing Nature, with a guiding principle of minimal interference with Nature to allow it to evolve and flourish in its own way.

Preference for organic agricultural practices, and an aversion to GMO technology and other intensive technology based crop and animal production practices.

\section{(c) Socio-ecological resilience critique}

(i) The RA: For the WAnth SER implications - see SWT items 1.2 and 3.1. For the SER erosion implications of $\mathrm{K}_{\mathrm{NR}}$ productivity-efficiency (optimisation) strategies (e.g., technology-based agricultural practices) - see SWT item 3.2.1.

(ii) The TA: For the EcoC implications of the TA, evident in its minimal interference with Nature principle, see SWT item 1.2. For the implications of the TA preference of human action that is SER supportive as opposed to erosion through $\mathrm{K}_{\mathrm{NR}}$ optimisation strategies as evident for the RA, see SWT item 3.2.1.

(iii) Conclusion: For this SWT item '3.2.2 Interests: Mechanism (non-human)':

Optimisation issues and the preference for the TA: as for SWT item '3.2.1. Interests: Mechanism (human)'.

WAnth and EcoC and the preference for the TA: as for SWT item '1.2 Primary goal area of focus'.

The TA is a preferred SW approach in SER terms.

\subsubsection{Interests: Population (human): For how many humans are interests to be satisfied?}

\section{(a) Reformist: Manage a SW to Population}

Stabilise current population, reduce very high rates of growth in some (mostly developing) countries, prevent reductions in some (mostly developed) countries.

Orientation to maximizing the human population that can be sustained within Reformist SW criteria.

(b) Transformational: Manage Population to a SW

Current human population seen as too high and unsustainable, and is an issue for all countries to address.

Long term reduction strategy required through collective non-coercive and non-discriminatory choice.

Reduction will benefit both humans and other species. 


\subsubsection{Interests: Population (human) (continued)}

\section{(c) Socio-ecological resilience critique}

(i) The RA: The rate of change in population numbers can exceed feedback mechanisms as to the sustainability of the population (Meadows et al., 1972), risking threshold breach. The current human population is not living within the Earth's $\mathrm{K}_{\mathrm{NR}}$ regenerative capacity (Clifton, 2010c; Footprint Network, 2010). The resulting $\mathrm{K}_{\mathrm{NR}}$ capital-base depletion reduces $\mathrm{K}_{\mathrm{NR}}$ spare capacity, increasing SES vulnerability, and risks of threshold breach. The RA resistance to population reduction limits humanity's response diversity to addressing ecological problems. A population maximisation strategy is inconsistent with maintaining spare capacity and keeping away from thresholds.

(ii) The TA: increases society's response diversity to address ecological problems by its willingness to embark on a human population reduction strategy to reduce human ecological impacts, and move to a position of spare capacity in humanity's use of $\mathrm{K}_{\mathrm{NR}}$.

(iii) Conclusion: For this SWT item '3.3.1. Interests: Population (human)':

The RA: (a) in some respects, supports strategies that are inherently SER eroding (i.e., maximisation of population) and in this respect is self-defeating, and (b) incorporates some human behaviours (e.g. greater rate of change, reduced response diversity in reducing human ecological impacts) that are less supportive of SER than the TA.

The TA is a preferred SW approach in SER terms.

\subsubsection{Interests: Population (non-human): For how many non-human forms of life are interests to be satisfied?}

(a) Reformist: Constrained to human interests - Weak Anthropocentrism

Non-human species diversity and population numbers mostly constrained to the extent needed to satisfy human instrumental objectives and self-interest pursuit.

Consistent with a WAnth view including maintaining critical levels of $\mathrm{K}_{\mathrm{N}}$ and satisfying Considered Human Preferences.

(b) Transformational: Flourishing - Ecocentrism

Non-human species flourish in their own right independently of human instrumental purposes or self-interest pursuit, characterised by abundance in biodiversity and in species population sizes.

Requires ceasing of human caused extinctions and significant increases in population numbers for most species.

(c) Socio-ecological resilience critique

(i) The RA: (a) is framed within the WAnth view with implications as per SWT item 1.2, and (b) is accepting of a degree of biodiversity loss, and is subject to the risks to ecosystem wellbeing that arise from this and the flow-on implications to human cultural diversity and human wellbeing (see SWT item 5.6.1 and 5.6.2).

(ii) The TA: (a) is framed within the EcoC view with implications as per SWT item 1.2, and (b) its focus on abundance in Nature is consistent with maintaining spare capacity and distance from thresholds.

(iii) Conclusion: For this SWT item '3.3.2. Interests: Population (non-human)':

The TA is preferred from a SER perspective due to its EcoC orientation and the implications that flow from this.

\section{Responsibility}

\subsection{Cause}

Current SW problems are solely human caused, that is, they are human society created problems.

Within this human context, various social actors are claimed to have contributed in different ways that can be considered within the Reformist and Transformational framework.

(a) Reformist: Wealth and Poverty, North and South

Production and consumption patterns of the wealthy - especially in the North, poverty in the South, and a lack of development in the South, are key causes of ecological harm and SW problems generally.

(b) Transformational: Wealth and the North

Production and consumption in the North, exploitation of the South by the North by both business and government, and efforts by the South to replicate Northern consumptive lifestyles, are the dominant causes of SW problems.

\section{(c) Socio-ecological resilience critique}

This SWT item '4.1. Responsibility - Cause', is not specifically suited to a SER critique.

The SER implications that flow from the RA and TA views (such as views on development in the South, or consumption patterns generally) are covered in the broader set of SWT items. 


\section{Responsibility (continued)}

\subsection{Remedy}

Humans are the only entity able to think about SW issues and to do something about them.

Within this human context, various social actors are claimed to have different remedial roles to play that can be considered within the Reformist and Transformational framework.

(a) Reformist: North and business led global green-and-just growth

North to make its production and consumption more green-and-just and help the South develop sustainably.

South to embrace Northern economic ideals in green-and-just ways consistent with a Reformist SW view.

Business has a key role in promoting global growth in partnership with government, based on a Reformist SW view.

Individual responsibility to make green-and-just consumer choices.

(b) Transformational: North restraint and sufficiency, South self determinism

North to bring its production and consumption within fair Earth-share limits and to stop exploiting the South.

South to find its own way of living sustainably and without replicating the unsustainable ways of the North.

Business size and power constrained by government with a preference for the small and local.

Government policies to limit scale of resource consumption and of distributional inequality.

Individual responsibility to adopt sufficiency lifestyles.

(c) Socio-ecological resilience critique

This SWT item '4.2. Responsibility - Remedy' incorporates many aspects covered in the broader set of SWT items, and conclusions drawn as to the preference for the RA for these other SWT items flow through to this item.

\section{General principles and concepts}

\subsection{Modelling a SW - the 3-Element Model}

(a) Reformist: Interlocking circles / 3-legged-stool / 3-pillars

Ecological, Social and Economic as separate but equally important and interrelated aspects of a SW.

Allows trade-offs consistent with Weak Sustainability (SWT item 5.3).

\section{(b) Transformational: Concentric circles}

Economy dependent on and constrained by Social, which is dependent on and constrained by Ecological.

3 versions of increasing strength in their TA characteristics: (a) boundaries of the 3 systems are clear and easily definable, (b) boundaries of the 3 systems are diffuse and permeable, and (c) single human 'activity and wellbeing' field within surrounding ecological, with no economic-system distinction, and the human 'activity and wellbeing' field boundary diffuse and permeable between it and the ecological.

\section{(c) Socio-ecological resilience critique}

(i) General: This SWT item is one of representing a SW. Its SER implications arise from the flow-on impacts to human decision making and behaviour that these representations encourage.

(ii) The RA: does not present a picture of: (a) limits and thresholds, (b) the need to maintain spare capacity in SESs, and (c) dependencies, depicting social, economic, and ecology as separate systems. This presents a false view of reality, risking human decision making being based on this false view (Cato, 2009; Dawe \& Ryan, 2003). The separate systems depiction supports a human-Nature dualism as per SWT item 1.2.

(iii) The TA: presents a picture of dependency, limits, and scale (Adams, 2006; H. Daly \& Farley, 2004), reinforcing concepts of thresholds and spare capacity, presenting an opportunity for these to be given meaningful consideration.

(iv) Conclusion: For this SWT item '5.1. Modelling a SW - the 3-Element Model':

The TA is a preferred approach as it paints a more accurate picture of the true state of the world within the SW context to which it is directed, and from which more appropriate SER supportive SW strategies might then flow.

\subsection{Justice: For all formulations of a SW:}

Achieving both Intra-generational (IntraG) and Inter-generational (InterG) justice is a necessary condition for a SW.

Ultimately it is justice in outcomes that is required.

Justice is multi-dimensional, and includes distribution (i.e. equity), recognition, capabilities, and participation.

(a) Reformist: Human focused and growth based

IntraG and InterG justice are relevant to humans only.

Overcoming poverty and a more equitable distribution of wealth requires continued economic growth.

InterG justice requires the passing on to future generations of an undiminished aggregate resource capital base (i.e., a weak sustainability approach - see SWT item 5.3). 


\subsection{Justice (continued)}

(b) Transformational: Humans and Nature focused and redistribution based IntraG and InterG justice are relevant to humans and to human acts towards Nature.

Human resource consumption based on a 'fair-Earth share' entitlement through redistribution of wealth and resource use, especially from the North to the South and from humans to Nature, not through more economic growth.

InterG justice requires the passing on to future generations of independently undiminished $\mathrm{K}_{\mathrm{N}}$ and $\mathrm{K}_{\mathrm{HF}}$ (i.e., a strong sustainability approach - see SWT item 5.3) based on EcoC principles.

\section{(c) Socio-ecological resilience critique}

This SWT item '5.2. Justice' incorporates many aspects covered in the broader set of SWT items, and conclusions drawn as to the preference for the RA from a SER perspective for these other SWT items flow through to this item.

\subsection{Human Interests - Resources}

\section{(a) Reformist: Weak Sustainability}

Sustainability of human interests satisfaction requires that the aggregate value of $\mathrm{K}_{\mathrm{N}}$ and $\mathrm{K}_{\mathrm{HF}}$ is sustained, with capital types substitutable beyond minimum critical values.

(b) Reformist and Transformational features: Strong Sustainability - Weak Anthropocentrism orientation

Sustainability of human interests satisfaction requires $\mathrm{K}_{\mathrm{N}}$ and $\mathrm{K}_{\mathrm{HF}}$ to be maintained separately, with $\mathrm{K}_{\mathrm{N}}$ and $\mathrm{K}_{\mathrm{HF}}$ seen as mostly complements and only marginally substitutable.

(c) Transformational: Strong Sustainability - Ecocentrism orientation

SSust reconstructed to incorporate EcoC principles, with $\mathrm{K}_{\mathrm{N}}$ as Nature rather than as aspects of Nature useful to humans.

$\mathrm{K}_{\mathrm{HF}}$ incorporates values beyond it being a form of capital.

(d) Socio-ecological resilience critique

(i) The RA: The WSust focus on maintaining critical $\mathrm{K}_{\mathrm{N}}$ is inconsistent with SER concepts of maintaining spare capacity and distance from thresholds. Limits to knowledge of critical $\mathrm{K}_{\mathrm{N}}$ levels risks unknowingly breaching thresholds. The WAnth issues are as per SWT item 1.2.

(ii) RA and TA features: SSust, in maintaining the $\mathrm{K}_{\mathrm{N}}$ and $\mathrm{K}_{\mathrm{HF}}$ capital bases independently, appears to overcome many of the WSust SER problems, but its WAnth orientation accepts the extinguishing of some forms of $\mathrm{K}_{\mathrm{N}}$ and some species loss (H. E. Daly, 1999), with WAnth paradigm issues applying as per SWT items 1.2 and '3.1.

(iii) The TA: The SSust approach within the TA-EcoC view overcomes the limitations of viewing Nature, and aspects of human society, as merely/mostly forms of capital. The EcoC issues are as per SWT item'1.2.

(iv) Conclusion: For this SWT item '5.3. Human Interests - Resources':

The RA, in some respects, supports strategies that are inherently SER eroding (i.e., a focus on critical $\mathrm{K}_{\mathrm{N}}$ )) and in this respect is self-defeating. WAnth issues are as per SWT item '1.2. Primary Goal area of focus'.

The both-RA-and-TA-features approach: WAnth issues are as per SWT item '1.2. Primary Goal area of focus'.

The TA is a preferred SW approach in SER terms.

\subsection{Risk and Precaution}

\section{(a) Reformist: Risk Management}

Maximisation and optimisation of human activity.

Ignorance and uncertainty are acknowledged, and risks from human activity are managed mostly through application of science and weaker forms of the Precautionary Principle (PP).

Risk aversion to change in social systems beyond marginal change based on green-and-just objectives.

(b) Transformational: Resilience Living

Socio-ecological Resilience Living pursued instead of human activity oriented to maximisation and optimisation.

Ignorance and uncertainty strongly recognised.

Stronger forms of the PP, and use of broad forms of knowledge in addition to scientific, are also used to address risk.

Risk tolerant of fundamental change to social systems and institutions to see primary SW goals achieved. 


\section{(c) Socio-ecological resilience critique}

(i) The RA: The focus on optimisation and maximisation, in its drive for efficiency of function, erodes SES diversity and redundancy, and reduces spare capacity, which increased the risks of threshold breach (Walker \& Salt, 2006). Its aversion to social system and institutional change beyond changes at the margin limits social response diversity and reduces adaptive capacity.

(ii) The TA: For this SWT item, the TA is by definition SER enhancing in its intent.

(iii) Conclusion: For this SWT item '5.3. Risk and Precaution':

The RA: (a) in some respects, supports strategies that are inherently SER eroding (i.e., maximisation and optimisation strategies) and in this respect is self-defeating, and (b) through an aversion to social system change, acts as a barrier to society's adaptive capacity.

The TA is a preferred SW approach from SER perspective.

\subsection{Growth and Development}

\section{(a) Reformist: Sustainable Growth}

Human wellbeing, including elimination of poverty and resolution of ecological problems, achieved through green-and-just, unlimited, and global GDP growth supported by free-trade, market based SW incentives, and a key role for the business sector.

Technology and human ingenuity as keys to resolving problems caused by growth and to overcome limits to growth.

(b) Transformational: Qualitative Development and Sufficiency

Human wellbeing progressed through green-and-just qualitative development and consumptive sufficiency, achieved through a steady-state economy, internationalisation not globalization, and a preference for consumption from local production.

Continued consumptive growth not sustainable or possible, and is a cause of ecological problems and of poverty.

(c) Socio-ecological resilience critique

(i) The RA: Continued global exponential GDP growth risks imposing a rate of change on social and ecological systems that outpaces feedback mechanisms (H. Daly \& Farley, 2004). The globalisation free-trade agenda homogenises the core global economic system (Mander, 2003; Shiva, 2005) which reduces: (a) economic system diversity, (b) human cultural diversity (SWT item 5.6.2), and (c) modularity between nations.

The strong focus on new technologies: (a) increases SES exposure to harms, (b) can impose a rate of change to SESs that outpaces SES feedback mechanisms and, (c) coupled with an efficiency strategy, can further the elimination of SES redundancy and spare capacity (see SWT item '5.3).

Alternates of a deliberate low or no-growth strategy are not entertained (Meadows et al., 2004), reducing society's adaptive capacity.

(ii) The TA: Growth in traditional GDP measures is not objected to as such, but rather GDP growth that is based on increased energy and material throughput. (H. Daly \& Farley, 2004; Gallopin, 2003; Meadows et al., 2004). This alternate view to growth, with a focus on non-consumptive satisfiers, addresses most of the SER concerns for the TA growth agenda.

Compared to globalisation, the TA internationalisation approach: (a) maintains a higher degree of modularity at the national level, and (b) the preference for consumption from local production strengthens feedback mechanisms by providing greater connect between consumption and its production impacts, reducing risks of threshold breach.

(iii) Conclusion: For this SWT item '5.3. 5.5. Growth and Development':

The RA: (a) in some respects, supports strategies that are inherently SER eroding (i.e., maximising growth, optimisation of resource productivity) and in this respect is self-defeating, and (b) through as aversion to social system change, acts as a barrier to social adaptive capacity.

The TA is a preferred SW approach from SER perspective.

\subsection{Diversity}

For all formulations of a SW, both biodiversity and cultural diversity are seen as being interdependent, mutually supportive, and necessary and equally important for there to be a SW.

\subsubsection{Biodiversity}

(a) Reformist: Constrained to human (weak anthropocentric) interests

Biodiversity loss is inevitable and acceptable but not below levels consistent with WAnth and not below either of: (a) critical $\mathrm{K}_{\mathrm{N}}$ levels for WSust, or (b) more significant than critical $\mathrm{K}_{\mathrm{N}}$ levels for SSust.

Consistent with mono-culture industrial agricultural practices including the precautionary use of GMO technology.

(b) Transformational: Flourishing

Biodiversity as a fundamental good and considered in ways consistent with ecocentric principles - humans need to live in ways that are biodiversity enhancing.

Sceptical of mono-culture industrial agricultural practices and the use of GMO technology - advocates a return to high diversity organic agricultural practices. 


\section{(c) Socio-ecological resilience critique}

(i) The RA: (a ) the WAnth view - as for SWT item 1.2, (b) the critical $\mathrm{K}_{\mathrm{N}}$ aspect - as for SWT item 5.3, and (c) mono-culture and technology based agricultural practices - as for SWT item 3.2.2. The loss of biodiversity that is acceptable under the RA is related to cultural-diversity loss in that biodiversity and cultural-diversity are interdependent and mutually supportive (Blewitt, 2008).

(ii) The TA: (a) the EcoC biodiversity view of the TA - as for SWT item 1.2, (b) the biodiversity enhancing view of the TA, as opposed to tolerance of biodiversity loss and management to critical $\mathrm{K}_{\mathrm{N}}$ levels - as for SWT item 5.3. The biodiversity enhancing views of the RA are related to cultural-diversity enhancement in that biodiversity and cultural-diversity are interdependent and mutually supportive (Blewitt, 2008)

(iii) Conclusion: For this SWT item '5.6.1. Biodiversity':

The RA: (a) in some respects, supports strategies that are inherently SER eroding (i.e., focus on critical $\mathrm{K}_{\mathrm{N}}$, and optimization of

$\mathrm{K}_{\mathrm{N}}$ productivity) and in this respect is self-defeating.

The TA is a preferred SW approach from SER perspective.

\subsubsection{Cultural diversity}

\section{(a) Reformist: Constrained within dominant socio-economic system}

Cultural diversity encouraged but exists within a dominant Reformist SW approach based on globalization, free trade, GDP growth, and a green-and-just consumer culture.

Incorporates concepts of multiculturalism, protection of indigenous rights, protection of items of cultural heritage and language, and the commodification of cultural goods and services.

\section{(b) Transformational: Flourishing}

Cultural diversity as a fundamental good incorporating all aspects of human society including economic systems.

Humans need to live in ways that are cultural diversity enhancing.

\section{(c) Socio-ecological resilience critique}

(i) The RA: Cultural diversity is limited to diversity within an homogenous core global economic system (Adu-Febiri, 2006; Banerjee \& Linstead, 2001), which reduces cultural diversity, including reductions in: (a) economic system diversity, (b) tradition knowledge, and (c) mechanisms to satisfy human needs beyond the consumption of market based goods and services. This reduces functional diversity (different societies meeting needs in different ways), and response diversity (the ability to respond to change by drawing on a diversity of knowledge from within different cultures) (Diesendorf, 1997; Dudgeon \& Berkes, 2003). Loss of cultural diversity impacts on biodiversity (SWT item 5.6.1).

(ii) The TA: The focus on abundance in cultural-diversity, including economic-system diversity, addresses most of the SER concerns of the RA. In particular, the greater cultural-diversity focus as compared to the RA: (a) increases society's response diversity by providing a broad range of knowledge, experience, and beliefs that can aid in the challenges humanity faces in moving to a SW (Adu-Febiri, 2006; Diesendorf, 1997; Dudgeon \& Berkes, 2003; UNESCO, 2001), and (b) increases the ability of humans to adapt to and live successfully in diverse ecological and social circumstances (Adu-Febiri, 2006; Dudgeon \& Berkes, 2003). Greater cultural diversity benefits biodiversity (SWT item 5.6.1).

(iii) Conclusion: For this SWT item '5.6.2. Cultural diversity':

The RA, in some respects, supports strategies that are inherently SER eroding (i.e., homogenisation of the core global economic system) and in this respect is self-defeating.

The TA is a preferred SW approach from SER perspective.

\subsection{Security}

(a) Reformist: Human Security focus - Targeted disarmament

Human Security focus: Focus on broad issues of Human Security and root causes of insecurity. Peace Dividend applied to progressing human and ecological wellbeing objectives.

Targeted disarmament: General reductions in military spending: Non-proliferation of, and elimination of, some types of weapons, especially weapons of mass destruction (WMD).

(b) Reformist and Transformational features: Human Security focus - Broad scale disarmament

Human Security focus: (as for 5.7 (a)).

Broad scale disarmament: Disarmament to minimal non-provocative defence capability, with no WMD: Stronger peace keeping capacity under international control.

(c) Transformational: Life Security focus - Broad scale disarmament

Life security focus: Focus on broad issues of security for humans and non-human species, and addressing root causes of insecurity. Peace Dividend applied to progressing SW objectives consistent with ecocentric principles.

Broad scale disarmament: (as for 5.7 (b)). 
(d) Socio-ecological resilience critique

(i) The RA: Supports a significant military capacity for all nations - well beyond defense capability. In this respect, it maintains various pressures that: (a) degrade the environment, increasing risks of ecological threshold breach, and (b) increase the exposure of SESs to military conflict actually occurring, and to its resulting harms, as compared to a world of significantly reduced military capability. The focus is on human security within the WAnth paradigm, with similar issues as per SWT item 1.2 .

(i) RA and TA features: The substantial reduction in military capacity offered under this approach addresses many of the issues of the RA. The WAnth orientation remains, with concerns as per SWT item 1.2.

(iii) The TA: An EcoC approach makes it unlikely that any military activity can be justified (Davion, 2004). Reasons include: (a) military engagement impacts negatively on non-human species who, from an EcoC perspective, deserve consideration of their interests, (b) similar issues applying for the conduct of military exercises and weapons testing that involve harm to non-human life, and (c) the use of animals as weapons or for weapons testing would be difficult, if not impossible, to justify (Davion, 2004). In addition to the general preference for the EcoC approach as per SWT item 1.2, these reasons add to society's functional and response diversity in avoiding military conflict and taking action to reduce the likelihood of it ever occurring.

(iv) Conclusion: For this SWT item '5.7. Security':

The RA incorporates a number of human behaviours (e.g. maintaining of significant military capability, and a general WAnth focus) that are less supportive of SER than the TA.

The RA-and-TA-features approach overcomes many of the RA concerns other than those stemming from its WAnth orientation.

The TA is a preferred SW approach from SER perspective. 